(2) Open Access Full Text Article

REVIEW

\title{
Intravenous ibuprofen: the first injectable product for the treatment of pain and fever
}

This article was published in the following Dove Press journal:

Journal of Pain Research

25 May 2010

Number of times this article has been viewed

\section{P Brandon Bookstaver \\ April D Miller \\ Celeste N Rudisill \\ LeAnn B Norris}

Department of Clinical Pharmacy and Outcomes Sciences, South Carolina College of Pharmacy, University of South Carolina Campus, Columbia, South Carolina, USA
Correspondence: P Brandon Bookstaver Department of Clinical Pharmacy and Outcomes Sciences, South Carolina College of Pharmacy, University of South Carolina Campus, 715 Sumter Street, Columbia, South Carolina, USA 29201 $\mathrm{Tel}+\mathrm{I}(803)$ 777-4786

Fax + I (803) 777-2820

Email bookstaver@sccp.sc.edu

\begin{abstract}
This paper reviews the current data on the use of the first approved intravenous ibuprofen product for the management of post-operative pain and fever in the United States. The management of acute and post-operative pain and fever with nonsteroidal anti-inflammatory agents (NSAIDs) is well documented. A search in Medline and International Pharmaceutical Abstracts of articles until the end of November 2009 and references of all citations were conducted. Available manufacturer data on file were also analyzed for this report. Several randomized controlled studies have demonstrated the opioid-sparing and analgesic effects of 400 and $800 \mathrm{mg}$ doses of intravenous ibuprofen in a series of post-operative patient populations. Two recent studies have also noted the improvement in fever curves in critically ill and burn patients. These data, along with pharmacokinetic and pharmacologic properties, are explored in this review, which addresses the clinical utility of a parenteral NSAID in a hospitalized patient for post-operative pain management and fever reduction. Further data on intravenous ibuprofen are needed to define long-term utilization, management of acute pain, and use in special populations.
\end{abstract}

Keywords: ibuprofen, intravenous, injectable, nonsteroidal anti-inflammatory drug

\section{Introduction}

Acute pain is a significant problem for inpatients and can occur secondary to acute illness or disease processes, trauma, or operative procedures. In the post-operative period, $80 \%$ of individuals suffer from post-operative pain with almost all describing it as moderate to severe. ${ }^{1}$ Physiologically, pain serves to alert individuals to tissue damage and to prevent further harm. However, in the acute inpatient setting, it often serves no useful purpose. Pain activates the sympathetic nervous system, increasing blood pressure, cardiac workload and respiratory rate. ${ }^{2}$ It impairs recovery by reducing mobility and physical activity. Despite the use of medications to control pain, it often remains undertreated and is a problem in hospitals and long-term care facilities.

Opioid analgesics are a mainstay in the management post-operative and acute pain in the inpatient setting. ${ }^{3}$ However, their use is often limited by adverse effects including respiratory depression, sedation, allergic reactions, and gastrointestinal events. Opioids are useful in mitigating the sensation of pain, but provide no benefits to the underlying disease process. Adjunctive agents for pain including non-steroidal anti-inflammatory agents (NSAIDs) may be used in combination with opioids. Combination therapy may help mitigate the side effects of both agents by reducing the total dose required. The anti-inflammatory properties of NSAIDs may also be useful in promoting healing 
and resolution of pain. NSAIDs inhibit the production of cyclooxygenase (COX)-1 and COX-2 enzymes and prevent the sensitization of pain receptors at the site of injury. The American Pain Society advocates the use of combination therapy including NSAIDs, for optimal pain control. ${ }^{4}$ The World Health Organization (WHO) includes NSAIDs in step 1 of the analgesic ladder for the treatment of mild to moderate pain. ${ }^{5}$ They are also included as adjuncts in the treatment of persistent and moderate to severe pain in steps 2 and 3 , respectively.

Recent data on the safety of COX-2 selective agents and fraudulent data in previously published pain studies have created significant clinical questions for clinicians. NSAIDs, particular COX-2 selective agents, have received great criticism related to an increased risk of cardiovascular events, including acute myocardial infarction, stroke, and coronary heart disease death. ${ }^{6-8}$ As a result, many agents were removed from the market worldwide. Likewise, information on the publication of fraudulent data has led to the retraction of a significant number of papers on the safety and efficacy of both COX-2 selective agents and NSAIDs in the post-operative setting. ${ }^{9}$ These significant controversies create a need for additional research in the field and for new products and formulations.

The antipyretic effects of NSAIDs are also well documented, resulting from inhibition of COX-1 to block the conversion of arachidonic acid to prostaglandins such as $\mathrm{PGE}_{2}$ in the immune response pathway. ${ }^{10}$ Fever is common in hospitalized patients and can be a result of infection, thrombosis, autoimmune disorders, malignancies, drugs, or other unknown causes. ${ }^{11}$ Reduction of fever not only offers substantial benefit to a patient's well-being but the metabolic compromise of sustained fever may potentiate risks associated with common co-morbidities encountered in hospitalized patients. Ibuprofen has been a primary agent of choice, along with acetaminophen, in the reduction of fever in both adults and children. Data have demonstrated equal efficacy between the two and offered pharmacokinetic advantages of ibuprofen in early onset and durable antipyretic effects after therapeutic concentrations have waned. ${ }^{12,13}$

Until recently, ketorolac (Toradol ${ }^{\circledR}$; Roche Laboratories, Nutley, NJ, USA) was the only NSAID available in parenteral form in the United States (US), and while it possesses known antipyretic effects, it is most frequently used in the management of acute and post-operative pain. Its use is limited by side effects that prohibit more than 5 days of therapy. ${ }^{14}$ Many practitioners also have the perception that it is more effective than oral ibuprofen. ${ }^{15}$ However, a review of studies examining both parenteral ketorolac and oral ibuprofen found that oral ibuprofen is as effective as ketorolac in the management of pain in emergency department patients. The authors also point out that the cost of oral ibuprofen is significantly less than parenteral ketorolac. Additional parenteral options are available outside the US where approved. Tenoxicam (Mobiflex ${ }^{\circledR}$; Roche Laboratories, United Kingdom) is an intravenous NSAID available in the United Kingdom. ${ }^{16}$ Parecoxib (Dynastat ${ }^{\circledR}$; European Union) is the first COX-2 inhibitor available for parenteral administration and is approved through much of Europe for short-term perioperative pain control much in the same way ketorolac $\left(\right.$ Toradol $^{\circledR}$ ) is used in the US. ${ }^{17}$ Two formulations of injectable diclofenac are available $\left(\right.$ Dyloject $^{\mathbb{R}}$; Javelin Pharmaceuticals, United Kingdom and Voltarol ${ }^{\circledR}$; Novartis, United Kingdom). Dyloj$\mathrm{ect}^{\circledR}$ is a novel injectable diclofenac formulation employing polyethylene glycol and benzyl alcohol as excipients, and is marketed in Europe and requires specific reconstitution slow infusion to minimize venous irritation. ${ }^{18}$ These products are not discussed further as a part of this review.

Oral ibuprofen is a commonly used NSAID with antipyretic, anti-inflammatory, and analgesic properties. It is a mainstay in the treatment of acute pain and fever and is readily available over the counter. Mechanistically, it acts both centrally and peripherally to reduce pain and fever. However, the use of ibuprofen in the inpatient or post-operative setting has previously been limited by the lack of a commercially available parenteral formulation. The drug's lipophilic properties have rendered production into an intravenous formulation difficult, but an intravenous form of ibuprofen (Caldolor ${ }^{\circledR}$; Cumberland Pharmaceuticals, Nashville, TN, USA) has recently been approved for use in the US. Previously, ibuprofen was available in a parenteral form as a lysine salt (Neoprofen ${ }^{\circledR}$ ) and an intravenous solution $\left(\right.$ Pedea $^{\circledR}$ ) only for treatment of patent ductus arteriosus in the neonatal population. ${ }^{19,20}$ Studies found that intravenous ibuprofen use improved pain control and reduced opioid use in the orthopedic and abdominal surgery setting as well as on fever reduction in the critically ill population. Its impact on pain management in the acute and post-operative settings, as well as long-term use remains undefined.

\section{Methods}

We conducted a Medline search for all articles published until the end of November 2009 using the MeSH terms "intravenous" and "ibuprofen". Additional searches of International Pharmaceutical Abstracts and EMBASE were conducted using the search terms "intravenous ibuprofen". Articles on the use of intravenous ibuprofen for indications other 
than pain management, including patent ductus arteriosus, and hypoxic ischemic encephalopathy, ibuprofen lysine, Pedea $^{\circledR}$, and animal data, were excluded. Reference lists from retrieved articles were also searched for additional relevant citations. Meeting abstracts were searched for pertinent citations. Unpublished data were also obtained by special request from Cumberland Pharmaceuticals (Nashville, TN, USA).

\section{Pharmacology Mechanism of action}

The mechanism of action and pharmacology of intravenous ibuprofen does not differ from the mechanism of oral ibuprofen. It works through reversible inhibition of COX-1 and COX-2 enzymes to decrease the conversion of arachidonic acid into prostaglandin endoperoxides including thromboxane and prostacyclin. ${ }^{21}$

The separation of functions of COX-1 and COX-2 is not straightforward, and a mixture of their activity is frequently responsible for the therapeutic and adverse effects of NSAIDs, including ibuprofen. $.^{21,22} \mathrm{COX}-2$ is produced in response to tissue injury, growth factors, tumor promoters and cytokines. ${ }^{21} \mathrm{COX}-1$ is found in most cells and maintains many physiologic housekeeping functions. Inhibition of prostaglandin $\mathrm{E}_{2}\left(\mathrm{PGE}_{2}\right)$ is responsible for the anti-pyretic properties of NSAIDs. The pain-relieving properties of NSAIDs relate to the inhibition of $\mathrm{PGE}_{2}$ and its effects peripherally and centrally. COX-1 and COX-2 in the spinal cord are released in response to painful peripheral stimuli to form prostaglandins which sensitizes peripheral nerve endings. Inhibition desensitizes the painful response. Centrally, inhibition of these enzymes in the spinal cord blunts the central sensitization and increase in excitability of spinal dorsal horn neurons seen in response to painful stimuli. Prostaglandins $\mathrm{PGE}_{2}$ and $\mathrm{PGI}_{2}$ are responsible for inflammation including edema formation and leucocyte infiltration through promotion of blood flow. Inhibition by COX enzymes reduces edema and suppresses the immunologic response associated with inflammation.

Interestingly, in animal models inhibition of COX enzymes prior to the onset of sepsis mitigated the physiologic abnormalities seen in sepsis and reduced mortality. ${ }^{23}$ In addition, a randomized controlled trial of ibuprofen in sepsis demonstrated an improvement in organ dysfunction in patients with hypothermia, but did not improve survival. ${ }^{24}$

\section{Adverse events}

It is this enzymatic inhibition of COX-1 and COX-2 that also leads to the hematologic, renal, and gastrointestinal adverse events associated with NSAIDs. ${ }^{21,22}$ Other side effects are idiosyncratic and less directly related to COX inhibition. COX-1 is responsible for the production of thromboxane $\mathrm{A}_{2}$, which is expressed in mature platelets. Thromboxane $\mathrm{A}_{2}$ acts as a platelet aggregator and enhances the effect of other platelet aggregators, including thrombin. While aspirin acts as an irreversible inhibitor of COX-1 and thromboxane $\mathrm{A}_{2}$ production in a dose-dependent manner, the activity of NSAIDs on platelets is temporary and reversible. It is incomplete inhibition of platelet aggregation that is believed to lead to the increased incidence of thrombotic adverse events with NSAIDs, including ibuprofen. ${ }^{21}$

Within the kidney, COX enzymes synthesize prostaglandins in the medulla and cortex. They play a key role in blood pressure regulation and maintenance of renal blood flow, especially in patients with long-standing chronic kidney disease or who are volume depleted. ${ }^{22}$ These effects are what often lead to the hypertension seen with NSAID therapy. The vasodilatory effects of prostaglandins and COX enzymes maintain renal blood flow and glomerular filtration, and inhibition of their production leads to decreased perfusion and a decline in renal function.

Synthesis of $\mathrm{PGE}_{2}$ is cytoprotective within the gastrointestinal (GI) tract and is protective against peptic ulcers, even without a reduction in acid secretion. ${ }^{21}$ Inhibition of COX-1 is thought to be responsible for the increased incidence of peptic ulcers and GI bleeding seen with NSAID therapy. Ibuprofen is non-selective, and its inhibition of COX-1 and COX-2 means that it is prone to GI side effects.

Bronchospasm can also be observed with NSAID therapy and is more prevalent in patients with a history of asthma or reactive airway disease. ${ }^{21}$ Inhibition of the COX enzymes by NSAIDs shifts metabolism of arachidonic acid from $\mathrm{PGE}_{2}$ and $\mathrm{PGI}_{2}$, which relax bronchial smooth muscle. ${ }^{22}$ Arachidonic acid instead is synthesized into leukotrienes that constrict airway smooth muscle.

\section{Drug interactions}

Like oral ibuprofen, the intravenous formulation interacts with several medications by either reducing protein binding, causing additive side effects, or inhibiting renal prostaglandin synthesis. Aspirin, the first and prototypical NSAID, has a similar mechanism of action and side effect profile as intravenous ibuprofen. When taken concomitantly, the protein binding of ibuprofen is reduced while the clearance of free ibuprofen is unchanged, although the effect of this interaction is unknown. ${ }^{25}$ The administration of aspirin or any other NSAID is not recommended in combination with intravenous 
ibuprofen due to additive COX inhibition and thus additional side effects. Concomitant administration of an NSAID with anticoagulants including warfarin and heparin products may also contribute to additional side effects including the risk of gastrointestinal bleeding. ${ }^{25}$ Patients who frequently use dual NSAID therapy have a higher risk of GI bleeding than users of either drug alone. In the elderly population, the risk of GI bleeding is higher and the interaction of these agents could be fatal.

NSAIDS when used in combination with angiotensin converting enzyme (ACE) inhibitors inhibit renal prostaglandin synthesis and diminish the antihypertensive effects of these agents. ${ }^{25}$ The inhibition lessens afferent arteriolar flow and causes a subsequent decrease in glomerular filtration rate, especially in elderly patients. The use of NSAIDS and ACE inhibitors in the elderly population has been found to be the main cause of drug-induced acute renal failure. ${ }^{26}$ Sodium depletion can also be a precipitating factor in renal failure, therefore the use of diuretics and NSAIDS may also lead to renal dysfunction. ${ }^{27}$ Lithium clearance can be decreased by $20 \%$ due to decreased prostaglandin production. ${ }^{25}$ Multiple case reports have documented the relationship between acute renal failure and the use of methotrexate and NSAIDS simultaneously. ${ }^{28}$ When using one of these agents concurrently with NSAIDS, extra monitoring and vigilance may be necessary to prevent lithium and methotrexate toxicity.

\section{Pharmacokinetics}

Ibuprofen is a racemic mixture of $[-] \mathrm{R}$ - and $[+] \mathrm{S}$-isomers. ${ }^{25}$ The $[+] \mathrm{S}-$ isomer is responsible for clinical activity according to in vivo and in vitro studies. The [-]R-isomer is slowly and incompletely interconverted into the active [+]S-species in adults. Active drug levels are maintained by circulating reservoir of the [-]R-isomer. As described by early models of the oral dosage form, ibuprofen best fits a linear or firstorder pharmacokinetic compartment model. Receipt of 5 to $10 \mathrm{mg} / \mathrm{kg}$ of oral ibuprofen suspension or solution results in a time to achieve maximum concentration $\left(\mathrm{t}_{\max }\right)$ of 0.75 to 1.5 hours. $^{12,29,30}$ Elimination half-life is approximately 1.6 hours. The AUC of plasma ibuprofen is dose-dependent due to the concentration-dependent protein binding where doubling of the dose ( 5 to $10 \mathrm{mg} / \mathrm{kg}$ ) results in a 1.6-fold increase in drug exposure. ${ }^{29}$ Ibuprofen is highly protein bound $(>99 \%$ bound). The protein binding is saturable and at concentrations $>20 \mu \mathrm{g} / \mathrm{mL}$ becomes nonlinear. The estimated volume of distribution is 0.11 to $0.21 \mathrm{~L} / \mathrm{kg}$ based on data from oral ibuprofen and there is a known age- and fever-related change. ${ }^{29-32}$

The terminal half-life of intravenous ibuprofen appears to be slightly above 2 hours (mean $=2.26$ hours) and consistent across all dosing ranges. ${ }^{25}$ Similar to data from the oral dosage form, antipyretic effects are delayed in relation to peak concentrations and last longer despite declining plasma ibuprofen concentrations. A summary of the pharmacokinetic parameters of intravenous ibuprofen from initial studies are detailed in Table 1. Important to note are the differences in infusion time among the three studies summarized (5- to 7-minute rapid infusion, 30-minute infusion, and 60-minute infusion). ${ }^{25,33,34}$ Infusion time greatly influences maximum concentration $\left(\mathrm{C}_{\max }\right)$ and $\mathrm{t}_{\max }$, which is typically immediately following the end of the infusion.

Table I Summary of pharmacokinetic parameters of intravenous ibuprofen

\begin{tabular}{|c|c|c|c|c|}
\hline Parameter & 100 mg dose & $200 \mathrm{mg}$ dose & $400 \mathrm{mg}$ dose & $800 \mathrm{mg}$ dose \\
\hline \multicolumn{5}{|l|}{ Study: Morris et al ${ }^{33}$} \\
\hline Number of patients & 31 & 30 & 31 & - \\
\hline $\mathrm{AUC}(\mu \mathrm{g} \cdot \mathrm{h} / \mathrm{mL})$ & $22.33(12.75)$ & $32.62(17.39)$ & $70.64(31.93)$ & - \\
\hline $\mathrm{C}_{\max }(\mu \mathrm{g} / \mathrm{mL})$ & $12.17(6.78)$ & I8.93 (I0.50) & $39.76(17.75)$ & - \\
\hline $\mathrm{T}_{1 / 2}(\mathrm{~h})$ & $2.47(1.15)$ & $2.11(1.05)$ & $2.26(0.95)$ & - \\
\hline \multicolumn{5}{|c|}{ Study: Intravenous ibuprofen product labeling; Data on file with Cumberland Pharmaceuticals ${ }^{\circledR 25,34}$} \\
\hline Number of patients & - & - & 12 & 12 \\
\hline $\mathrm{AUC}(\mu \mathrm{g} \cdot \mathrm{h} / \mathrm{mL})$ & - & - & $109.3(26.4)$ & $192.8(\mid 8.5)$ \\
\hline $\mathrm{C}_{\max }(\mu \mathrm{g} / \mathrm{mL})$ & - & - & $39.2(15.5)$ & $72.6(13.2)$ \\
\hline $\mathrm{T}_{1 / 2}(\mathrm{~h})$ & - & - & $2.22(20.1)$ & $2.44(12.9)$ \\
\hline \multicolumn{5}{|l|}{ Study: Pavliv et al ${ }^{34}$} \\
\hline Number of patients & - & - & - & 12 \\
\hline $\mathrm{AUC}(\mu \mathrm{g} \cdot \mathrm{h} / \mathrm{mL})$ & - & - & - & $195.7(37.3)$ \\
\hline $\mathrm{C}_{\max }(\mu \mathrm{g} / \mathrm{mL})$ & - & - & - & $120.3(13.5)$ \\
\hline $\mathrm{T}_{1 / 2}(\mathrm{~h})$ & - & - & - & $2.0(0.5)$ \\
\hline
\end{tabular}


In a pharmacokinetic study of 24 healthy volunteers, doses of $400 \mathrm{mg}$ and $800 \mathrm{mg}$ were administered over 60-minute infusions. ${ }^{25}$ The association between the different doses demonstrates a $\mathrm{C}_{\max }$ ratio of 1.7 and an $\mathrm{AUC}$ ratio of 1.8 for the $400 \mathrm{mg}$ and $800 \mathrm{mg}$ doses, respectively. ${ }^{25}$ These data are similar to the pharmacokinetics observed with oral ibuprofen. Unpublished data of a randomized, cross-over, placebo controlled study, examined the pharmacokinetic profile of an 800 -mg dose given via rapid infusion over 5 to 7 minutes. ${ }^{34}$ Twelve healthy volunteers, mean age of 31.7 years and mean weight of $77 \mathrm{~kg}$, were enrolled. At approximately three hours post-dose, the mean serum concentration was $20 \mu \mathrm{g} / \mathrm{mL}$ with a half-life of approximately 2 hours. The $\mathrm{AUC}_{\text {t-inf }}$ of $196 \mu \mathrm{g} \cdot \mathrm{h} / \mathrm{mL}( \pm 37)$ is similar to previous pharmacokinetic studies in subjects receiving $800 \mathrm{mg}$. Compared to oral dosing of $800 \mathrm{mg}$ in the same population, the AUCs were very similar (196.4 vs 195.7), but $\mathrm{C}_{\text {max }}$ nearly doubled (120.3 vs 62.8$)$ with significantly shorter time to peak concentrations (6.5 vs 90 minutes).

In a multi-center, randomized, double-blind, placebocontrolled trial conducted by Morris et al 120 hospitalized patients ( $88 \mathrm{men}, 32$ women) with temperatures of $38.3^{\circ} \mathrm{C}$ or greater were randomized to intravenous ibuprofen $400 \mathrm{mg}$, $200 \mathrm{mg}, 100 \mathrm{mg}$ or placebo, administered every 4 hours for 24 hours over a 30 -minute infusion. ${ }^{33}$ Both first-dose and steady state kinetics were evaluated in all 3 dosing arms. Of note, $44 \%$ of these patients were critically ill and all patients were febrile. At all evaluable time points, mean ibuprofen concentrations were significantly lower in critically ill subjects compared to non-critically ill. Although the influence of fever specifically within these subgroups cannot be evaluated, changes in volume of distribution in a critically ill patient may influence the lower $\mathrm{C}_{\max }$ and AUC. For dosing, this may implicate the need for higher than $400 \mathrm{mg}$ doses in critically ill populations if desired clinical response is not achieved. Data regarding the clinical outcomes of this study are detailed in later sections. Clinically, $800 \mathrm{mg}$ doses have proven effective in a critically ill burn population, however the pharmacokinetic profiles have not been reported. ${ }^{35}$

\section{Pediatrics}

Specific studies of the intravenous ibuprofen formulation have not been conducted in pediatrics. Pharmacokinetic analyses in febrile children receiving oral ibuprofen demonstrated obtainment of peak concentrations 0.75 to 1.5 hours following oral dosages of 5 to $10 \mathrm{mg} / \mathrm{kg} .{ }^{12,29,30,36}$ Volume of distribution was similar to that found in adults, 0.16 to $0.18 \mathrm{~L} / \mathrm{kg}$. Although oral absorption from the gastrointestinal tract was complete, there was a delay in maximum antipyretic effects up to 2.5 hours following achievement of peak concentrations.

Age-related phenomena have been well described with ibuprofen. Wilson et al demonstrated a difference in antipyretic response in children $>6$ years of age compared to those $\leq 6$ years old, with no apparent differences in pharmacokinetic properties. ${ }^{36}$ These same investigators also reported pharmacokinetic differences in younger children $(<2.5$ years of age) where an increased ibuprofen clearance was observed compared to older children, likely due to a larger volume of distribution. ${ }^{29}$

Also, consistent with product labeling of oral ibuprofen products, children with a temperature $>39.2^{\circ} \mathrm{C}$, a dosage increase to $10 \mathrm{mg} / \mathrm{kg}$ is recommended to compensate for the reduced antipyretic effect. Kauffman et al observed a faster onset and greater antipyretic effect in children $<1$ years of age, compared to those $>6$ years old. ${ }^{12}$ This was independent of any significant differences in pharmacokinetic properties. Data using alternative formulations of intravenous ibuprofen in special populations of pediatrics are described below regarding cerebrospinal fluid (CSF) penetration and use in cystic fibrosis patients. Although, there are no current recommendations for intravenous ibuprofen in pediatrics, the rapid achievement of peak concentrations could prove clinically beneficial when timely antipyretic effects are desired.

\section{Central nervous system}

A single pharmacokinetic study in pediatrics investigated the CSF and plasma concentrations of intravenous ibuprofen (Ibuprof von ct. Germany) in children following inguinal surgery. ${ }^{37}$ Thirty-six children, aged 3 months to 12 years (median 40 months) received a single intravenous injection of ibuprofen $(10 \mathrm{mg} / \mathrm{kg})$. CSF concentrations ranged between 15 and $541 \mu \mathrm{g} / \mathrm{L}$, with the peak concentrations measured 30 to 38 minutes after dosing. At the onset of post-surgical pain, 186 to 266 minutes following ibuprofen injection, the correlating plasma concentrations ranged between 10 and $25 \mathrm{mg} / \mathrm{L}$ (median $21 \mathrm{mg} / \mathrm{L}$ ). Ibuprofen was over 99\% protein bound, with a median unbound/total plasma concentrations ratio of 0.0020. All ibuprofen CSF concentrations exceeded that of unbound plasma concentrations in all samples collected 30 minutes post-dose. These results suggest a rapid movement of drug into the CSF and sustained plasma analgesic concentrations for 2 to 4 hours following a single $10 \mathrm{mg} /$ $\mathrm{kg}$ dose in pediatrics undergoing inguinal surgery. A study examining CSF concentrations in adults receiving a single 
$800 \mathrm{mg}$ oral dose demonstrated a similar peak CSF concentration, obtained at 3 hours as opposed to 30 minutes following intravenous administration. ${ }^{38}$ In patients undergoing similar short-term recovery or outpatient surgeries, this correlates well to being able to provide the patient with a second dose or discharge dose 3 to 4 hours post surgery.

Penetration into the CSF is governed partially by the lipophilicity of the agent. Ibuprofen, similar to other NSAIDS, is lipophilic, and thus possesses the ability to readily cross the blood-brain and blood-CSF barriers. At physiologic $\mathrm{pH}$ (7.4), the apparent partition coefficient is 1.1 , which suggests ready diffusion into the CSF; however, ibuprofen is almost totally ionized at these conditions (99\%), restricting movement into the CNS. ${ }^{39}$ The highly protein bound nature of ibuprofen may limit its movement across the blood-CSF and blood-brain barrier, as only unbound drug can readily diffuse. Additional mechanisms have been suggested to limit diffusion such as efflux mechanisms at the blood-CSF barrier including multidrug resistance proteins and organic anion transport systems. ${ }^{40-42}$ By comparison to ketoprofen and indomethacin, ibuprofen seems to more readily cross into the $\mathrm{CNS}$, with less interpatient variability. ${ }^{43,44}$

\section{Cystic fibrosis}

As with many drugs, cystic fibrosis (CF) patients appear to exhibit altered pharmacokinetics of ibuprofen in comparison to healthy controls. The primary pharmacokinetic alterations in CF patients include reduced absorption, increased volume of distribution, and more rapid clearance. ${ }^{45}$ The reduction in absorption of oral ibuprofen encountered in patients with $\mathrm{CF}$ leads to a reduction in $\mathrm{C}_{\max }$ and $\mathrm{AUC}$ of $27 \%$ and $46 \%$, respectively, compared to healthy children. ${ }^{46}$ Although no data exist with the intravenous formulation specifically in this population, this route of administration may be particularly advantageous in avoiding the interpatient variability and reduced absorption encountered with alternative routes of administration.

\section{Dosage and administration}

The lowest effective dose should be used for the shortest duration consistent with individual patient treatment goals. The maximum daily dose is $3200 \mathrm{mg} .{ }^{25}$ Patients should be hydrated prior to administration of intravenous ibuprofen to reduce the risk of renal adverse reactions. For analgesia, $400 \mathrm{mg}$ to $800 \mathrm{mg}$ should be administered intravenously every 6 hours as necessary. For fever $400 \mathrm{mg}$ intravenously followed by $400 \mathrm{mg}$ every 4 to 6 hours or 100 to $200 \mathrm{mg}$ every
4 hours should be administered as necessary. According to the product labeling, the minimum infusion time for intravenous ibuprofen is 30 minutes. A randomized, cross-over, placebo controlled study, examined the safety and tolerability of a single 800-mg dose given via rapid infusion over 5 to $7 \mathrm{~min}$ utes in 12 healthy volunteers, and 4 of 12 subjects reported infusion-related site pain. ${ }^{34}$ Rapid infusion, when tolerated, may be pragmatic in the post-operative or intensive care unit setting resulting in rapid achievement of $\mathrm{C}_{\text {max }}$ (see Pharmacokinetics section), also aiding in administration decisions at the patient's bedside. Intravenous ibuprofen is available as a $400 \mathrm{mg} / 4 \mathrm{~mL}$ single-dose vial and $800 \mathrm{mg} / 8 \mathrm{~mL}$ single-dose vial. ${ }^{25}$ The stopper in the intravenous ibuprofen vial does not contain natural rubber latex, drug natural rubber, or blends of natural rubber.

\section{Drug formulation}

Ibuprofen, $( \pm)-2-(p$-isobutylphenyl) propionic acid, is the active ingredient in intravenous ibuprofen $\left(\right.$ Caldolor $\left.^{\circledR}\right){ }^{25}$ Arginine is also contained in this product to assist with stability at a molar ratio of $0.92: 1$ of arginine:ibuprofen. Ibuprofen is soluble in agents such as acetone and ethanol, but only slightly soluble in water $(<1 \mathrm{mg} / \mathrm{mL})$. To prevent serious phlebitis during administration, the final concentration during admixture must be $4 \mathrm{mg} / \mathrm{mL}$ or less. Intravenous ibuprofen is stable when $0.9 \%$ sodium chloride injection USP (normal saline), 5\% dextrose injection USP (D5W), or lactated Ringer's solution is used as the diluent. ${ }^{47}$ Intravenous ibuprofen is available as a $400 \mathrm{mg} / 4 \mathrm{~mL}$ single-dose vial and $800 \mathrm{mg} / 8 \mathrm{~mL}$ single-dose vial. Once diluted, intravenous ibuprofen remains stable for 7 days at room temperature in standard lighting.

\section{Clinical evaluation}

Results from an increasing number of clinical studies demonstrate an interesting analgesic and antipyretic profile of intravenous ibuprofen in the management of mild to moderate pain, management of moderate to severe pain as an adjunct to opioid analgesics, and reduction of fever. Studies are reviewed based on their clinical indication.

\section{Use in post-operative pain}

Three randomized, double-blind, placebo-controlled trials of intravenous ibuprofen to evaluate the safety and efficacy as a post-operative analgesic have been published to date. The first examined the effects of intravenously administered ibuprofen 400 and $800 \mathrm{mg}$ every 6 hours in post-operative 
pain management. ${ }^{3}$ Subjects were recruited through 17 sites within the United States, Australia, and the Republic of South Africa between February 2005 and September 2006. Subjects were scheduled to undergo elective, single-site orthopedic or abdominal surgery and were expected to require hospitalization and postoperative analgesia with intravenously administered morphine for $>14$ hours after surgery. After surgery, all patients received morphine by hospital staff on patient request or patient-controlled analgesia (PCA) pump ( 1 to $2 \mathrm{mg}$ every 5 minutes) and were assigned in a 1:1:1 ratio using a stratified, blinded by site, randomization scheme to receive ibuprofen $400 \mathrm{mg}$ intravenous, ibuprofen $800 \mathrm{mg}$ intravenous, or inactive vehicle (placebo), every 6 hours for a total of 8 doses, over the first 48 hours of the study. After the initial 8 doses, the protocol allowed for continued administration of intravenous ibuprofen or placebo every 6 hours, at the discretion of the investigator, for control of postoperative pain for a total of up to 120 hours ( 5 days). The primary outcome measure was the mean amount of morphine administered during the first 24 hours following surgery. Statistical analyses of the efficacy end points were conducted on the intent-to-treat (ITT) population and the efficacy-evaluable (EE) population (all patients who received at least 4 doses of intravenous ibuprofen or placebo within 60 minutes of the scheduled administration time). A total of 406 patients were enrolled and were all included in the ITT population, and a total of 342 patients who received the first 4 doses of study medication were included in the EE population. In the ITT population, median morphine use was significantly reduced during the first 24 hours of administration of study drug in patients who received ibuprofen $800 \mathrm{mg}$ intravenous every 6 hours by $22 \%$ vs placebo $(P=0.030)$; the difference in morphine use between the ibuprofen $400 \mathrm{mg}$ intravenous and placebo groups was not significant.

In a second multi-center, randomized, double-blind, placebo-controlled trial, women who had undergone an elective abdominal hysterectomy, were randomized and treated with intravenous ibuprofen $800 \mathrm{mg}$ or placebo administered every 6 hours started intra-operatively. ${ }^{48,49}$ Subjects also received morphine administered on an as needed basis. Efficacy was demonstrated by measuring the patients' morphine usage during the post-operative period and self assessment of pain at rest and with movement using a visual analog scale (VAS). The study found that patients receiving $800 \mathrm{mg}$ of intravenous ibuprofen had 19\% less median morphine use. Subjects receiving intravenous ibuprofen had a $21 \%$ and $14 \%$ reduction in pain intensity on the VAS at rest and with movement, respectively. The median morphine usage is summarized in Table 2 .

In a third multi-center, randomized, double-blind, placebo-controlled trial, a total of 185 patients undergoing elective knee or hip orthopedic surgery were randomly assigned in 1:1 ratio to receive either $800 \mathrm{mg}$ intravenous ibuprofen or placebo every 6 hours. ${ }^{50}$ In addition, all patients had access to morphine, and the first dose of study medication was administered prior to surgery. Efficacy was demonstrated by measuring the patients' self-assessment of pain with movement and at rest using a VAS and a verbal response scale (VRS). Morphine use during the post-operative period was also compared between groups as an efficacy measure. Patients receiving $800 \mathrm{mg}$ intravenous ibuprofen compared to placebo experienced a significant reduction in pain as measured by the area under the curve of the VAS (VAS-AUC) with movement and at rest for the post-operative period, study hours 6 to $28(P<0.001)$. There was a $25.8 \%$ reduction in mean VAS-AUC (with movement) $(P<0.001)$ and a $30.9 \%$ reduction in morphine usage $(P<0.001)$ in patients receiving intravenous ibuprofen. There was a $31.8 \%$ reduction in mean VAS-AUC (at rest) and a 20.2\% reduction in mean VRS in patients receiving intravenous ibuprofen. There was not a significant difference in the number of adverse events observed between the treatment groups.

\section{Use for fever}

Morris et al investigated intravenous ibuprofen to reduce fever. ${ }^{33}$ One hundred twenty hospitalized adult patients at nine sites ( 88 men, 32 women) with temperatures of $38.3^{\circ} \mathrm{C}$ or greater were randomized to intravenous ibuprofen $400 \mathrm{mg}$, $200 \mathrm{mg}, 100 \mathrm{mg}$ or placebo, administered every 4 hours for 24 hours. Fifty-three of the 120 patients (44\%) were critically ill and receiving mechanical ventilation and/or vasopressor support. The primary objective was to evaluate the efficacy of $400 \mathrm{mg}$ intravenous ibuprofen on reducing fever to greater than or equal to $38.3^{\circ} \mathrm{C}$, determined by the percentage of subjects with temperature less than $38.3^{\circ} \mathrm{C}$ at 4 hours after administration of a single dose, as compared with the efficacy of parallel placebo treatment. Each of the three intravenous ibuprofen doses, $100 \mathrm{mg}, 200 \mathrm{mg}$, and $400 \mathrm{mg}$, resulted in a statistically greater percentage of patients with a reduced temperature $(<3)$ after 4 hours, compared to placebo $(61 \%, 70 \%$, $77 \%$ and $32 \%$, respectively). Temperature decreased in both the critically ill and non-critically ill subjects receiving intravenous ibuprofen versus those receiving placebo. However, this study was not designed to show differences in efficacy 
Table 2 Summary of intravenous ibuprofen clinical studies

\begin{tabular}{llll}
\hline Author & Study aim & Treatment arm & Results \\
\hline Kroll et al ${ }^{49}$ & Efficacy and safety in adult & $800 \mathrm{mg}$ IV or placebo every & Efficacy: morphine requirements in \\
& abdominal surgery patients & 6 hours + PRN morphine & ibuprofen group $43.7 \mathrm{mg}$ and placebo \\
& $(\mathrm{N}=319)$ & & $56 \mathrm{mg}(P<0.00 \mathrm{I})$ \\
& & Safety: no differences in adverse events
\end{tabular}

$\begin{array}{lll}\text { NCT00606489, } & \text { Efficacy (fever and pain) and } & 800 \mathrm{mg} \text { IV or placebo every } \\ \text { Cumberland } & \text { safety in pediatric and adult burn } & 6 \text { hours during I20-hour } \\ \text { Pharmaceuticals, Inc. }{ }^{56} & \text { patients }(\mathrm{N}=6 \mathrm{I}) & \text { treatment period }\end{array}$

Morris et $\mathrm{al}^{33}$

Efficacy (fever) and safety in hospitalized adult patients $(N=120 ; \sim 33 \%$ were critically illa)
100 mg, 200 mg, 400 mg IV or placebo every 4 hours for a total of 6 doses

\begin{abstract}
NCT00470600,
Cumberland

Pharmaceuticals, Inc. ${ }^{50}$

Efficacy and safety in hospitalized adult orthopedic surgery patients $(N=185)$
\end{abstract}

Southworth et $\mathrm{al}^{3}$
$800 \mathrm{mg}$ IV or placebo every 6 hours + PRN morphine
$400 \mathrm{mg}, 800 \mathrm{mg}$ IV or placebo every 6 hours for 8 doses + morphine PCA
Efficacy and safety in adult abdominal (73\%) or orthopedic surgery patients $(27 \%)(\mathrm{N}=406)$
Efficacy: significant reduction in fever in $800 \mathrm{mg}$ ibuprofen versus placebo in first 24 hours as measured by AUC-T $(P=0.03)$ Safety: no significant difference between the two groups for adverse events; no differences between the groups for laboratory values, frequency of blood transfusions, or bleeding

Efficacy: proportion of patients $<38.3^{\circ} \mathrm{C}$ at 4 hours post initial dose: placebo (32\%), $100 \mathrm{mg}(61 \%), 200 \mathrm{mg}(70 \%)$, $400 \mathrm{mg}(77 \%)(P<0.05$ for all treatment arms versus placebo) Safety: no statistical significant differences in serious adverse events between treatment arms through study day 28

Efficacy: morphine requirements reduced by $30.9 \%$ compared to placebo $(P<0.00 \mathrm{I})$; reduction of $20 \%-32 \%$ in mean VAS-AUC (at movement and rest) and VRS;

Safety: significant increase in vomiting in the treatment arm versus placebo

Efficacy: morphine requirements reduced by $22 \%$ in the $800 \mathrm{mg}$ arm $(P=0.03)$, $3 \%$ in the $400 \mathrm{mg}$ arm $(P=\mathrm{NS})$ versus placebo; $800 \mathrm{mg}$ arm resulted in significant reductions in pain earlier than $400 \mathrm{mg}$ arm when compared to placebo ( $1-6$ hours versus 6-12 hours)

Safety: no significant differences in serious adverse events between treatment arms through study day 14

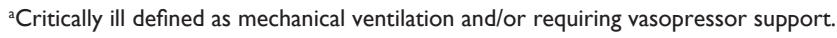

Abbreviations: IV, intravenous; PRN, as needed; AUC-T, area under the temperature curve; VAS, visual analog scale; VRS, verbal response scale; PCA, patient-controlled analgesia.

between treatment doses. This study may demonstrate that higher doses, such as $800 \mathrm{mg}$ are required for fever reduction in critically ill patients.

The antipyretic effects have also been demonstrated in a critically ill burn population. ${ }^{35,51}$ Patients in this randomized, double-blind, placebo-controlled trial were enrolled from 5 burn centers or units both domestic and international. A total of 61 adult patients with second- or third-degree burns over at least $10 \%$ body surface area were included. Patients received either placebo or $800 \mathrm{mg}$ intravenous ibuprofen every 6 hours for 5 consecutive days. Significant reductions in fever curve were noted in the first 24 hours.

\section{Use in arrhythmias}

Threatening arrhythmias were suppressed following the administration of intravenous ibuprofen during electrical storm. ${ }^{52}$ In 4 patients admitted with a diagnosis of cardiomyopathy and atrioventricular block secondary to an acute ischemic insult, lifethreatening ventricular tachyarrhythmias responded to a single intravenous $400 \mathrm{mg}$ dose of ibuprofen. In each case, the arrhythmias were refractory to amiodarone treatment. This is the first report of suppression of arrhythmias through the administration of an anti-inflammatory medication. Although, this provides some evidence for ibuprofen in arrhythmias, more data on its use for this purpose are needed before widespread use. 


\section{Use in pediatrics}

Currently the use as an analgesic in pediatrics is limited to a pharmacokinetic study not designed to evaluate efficacy. ${ }^{37}$ As described above, 36 children received a single $10 \mathrm{mg} / \mathrm{kg}$ dose of intravenous ibuprofen over 5-minute rapid infusion prior to surgery using spinal anesthesia. Additionally, most children were premedicated with midazolam and ketamine prior to receiving bupivicaine for spinal anesthesia. The median time to pain after surgery was 138 minutes (range 57 to 231 minutes) and after ibuprofen injection was 213 minutes (range of 186 to 266 minutes). Three children received a second dose of ibuprofen in the post-anesthesia care unit, while 25 received ketoprofen. Ten children reported severe pain defined as $>3 / 10$ at rest or $>5 / 10$ with 20 - $N$ compression post surgery that required opioid rescue. Data using intravenous ibuprofen in burn patients included pediatric and adult patients. However, pediatric specific data are not available..$^{35}$

Additional data in pediatrics focuses on infantile use in patent ductus arteriosus with alternative intravenous ibuprofen products. These data are not reviewed here. ${ }^{53-55}$

\section{Safety and tolerability Post-operative patients}

Southworth and colleagues determined that 91\% (368/406) of patients experienced treatment-emergent adverse events when comparing morphine PCA combined with $400 \mathrm{mg}$ or $800 \mathrm{mg}$ of intravenous ibuprofen or placebo. ${ }^{3}$ Nausea, vomiting, and constipation occurred most frequently in all study arms including placebo with fewer side effects observed with ibuprofen. There was significantly less nausea with $400 \mathrm{mg}$ ibuprofen relative to placebo. This apparent reduction in gastrointestinal side effects is likely related to a reduction in opioid use and a corresponding reduction in their adverse effects. Pyrexia was also significantly reduced in the $400 \mathrm{mg}$ and $800 \mathrm{mg}$ ibuprofen arms as compared to placebo. In the $800 \mathrm{mg}$ ibuprofen arm, a statistical reduction was found in the incidence of dizziness as compared to placebo. Laboratory values including renal function and vital sign measurements were similar throughout the study in all three groups. The incidence of bleeding and bruising did not differ significantly between the groups. Overall, the total blood units transfused during the study were similar amongst all three arms. Of the 406 patients treated in this study, there were no deaths reported. Discontinuation of the study drug occurred on day 5 of 14 for all 406 patients. Most of these patients were able to tolerate oral pain medication on day 5 , and therefore the intravenous therapy was discontinued.
In 319 female patients undergoing elective abdominal hysterectomy, randomized to receive $800 \mathrm{mg}$ intravenous ibuprofen every 6 hours or placebo, there were no differences in treatment-emergent adverse events. ${ }^{48,49}$ Clinical laboratory assessments including renal and hepatic function were similar between the two groups and the most common side effects were similar to those associated with oral ibuprofen use. Serious adverse effects were determined to be related to the hysterectomy procedure itself, and not study drug. Similar results were found in the 185 patients undergoing orthopedic elective knee or hip surgery, with the exception of a difference in gastrointestinal side effects. There were significantly more patients who experienced emesis in the ibuprofen group as compared to placebo, however significantly more patients in the placebo group reported dyspepsia.

A study of hospitalized burn patients found no significant differences between the group treated with intravenous ibuprofen $800 \mathrm{mg}$ and placebo. ${ }^{51,56}$ No significant differences in the incidences leucocytosis and anemia were found. Five subjects experienced 6 serious adverse events in the ibuprofen group and 3 subjects experienced 6 adverse events in the placebo group. There was no difference in the clinical laboratory assessments (serum creatinine levels, hemoglobin, platelet counts, prothrombin time, or activated partial thromboplastin time) between the two groups. The frequency of blood transfusions was similar in both groups. Findings from this study were similar to previous studies and demonstrated a relatively favorable side effect profile.

\section{Critically ill patients}

Morris and colleagues evaluated the safety and efficacy of intravenous ibuprofen in 120 hospitalized adult febrile patients. ${ }^{33}$ Between the $100 \mathrm{mg}, 200 \mathrm{mg}$, and $400 \mathrm{mg}$ arms of intravenous ibuprofen as compared to placebo, there were no statistically significant differences when comparing the three groups except for the incidence of bacteremia. In the $100 \mathrm{mg}$ intravenous ibuprofen group, there were 4 cases of bacteremia $(13 \%)$ as compared to $0 \%$ in the placebo group. Since this increase was not observed in any other ibuprofen arms, it is unlikely that these events were associated with the study drug as this side effect. Like the previous studies, there were no differences found between the three groups in terms of serious adverse events, bleeding or bruising, laboratory values, hemoglobin/hematocrit values, or transfusion requirements.

\section{Bleeding}

One of the major concerns in using intravenous ibuprofen in the acute care setting is the risk of bleeding. In a 30-day 
prospective, phase III, randomized, placebo-controlled, double-blind study that enrolled 450 patients with severe sepsis syndrome, intravenous ibuprofen was administered to determine the efficacy and safety of intravenous ibuprofen in reducing mortality. ${ }^{23}$ Patients received $10 \mathrm{mg} / \mathrm{kg}$ of intravenous ibuprofen every 6 hours times 8 doses for a maximum infusion of $6400 \mathrm{mg}$ intravenous or placebo after diagnosis of sepsis syndrome. Evaluation of bleeding events, tranfusion requirements, and serial laboratory measurements were documented (hemoglobin, hematocrit, platelets, pro-thrombin time, and activated partial thromboplastin time) at baseline and $0,20,44,72,96$, and 120 hours after initiation of therapy. There were 15 events in the ibuprofen arm and 25 events in the placebo arm that could be classified as bleeding complications Of the 40 total bleeding events, the majority of these were related to gastrointestinal bleeding (19 placebo, 9 ibuprofen). Two patients in the placebo arm experienced a cerebrovascular accident compared to 3 patients in the ibuprofen arm. One patient in the ibuprofen arm experienced a pulmonary hemorrhage. At baseline, 117 patients received transfusions with an additional 146 in the placebo group and 153 in the ibuprofen group receiving transfusions at the onset of dosing through 120 hours. Administration of total blood products including packed red blood cells, platelets, fresh frozen plasma and albumin were similar between the two groups. In the ibuprofen group, the average units transfused per patient was $3.66 \pm 0.33$ units versus $3.34 \pm 0.26$ units in the placebo group. Of the laboratory values assessed for bleeding, no statistical differences between the groups were observed at any time point $(P>0.05)$. Overall, patients treated with intravenous ibuprofen in the setting of sepsis syndrome where the bleeding risk is extremely high, there were no differences in bleeding events, transfusion requirements, or coagulation abnormalities.

\section{Infusion-related reactions}

According to the package insert, intravenous ibuprofen infusion time should be no less than 30 minutes due to concerns of infusion related reactions. ${ }^{25}$ In a pharmacokinetics study conducted by Pavliv, 12 healthy patients were administered $800 \mathrm{mg}$ of intravenous ibuprofen over 5 to 7 minutes + oral placebo followed by a 7-day washout period when they received $800 \mathrm{mg}$ of ibuprofen + placebo intravenous ibuprofen over 5 to 7 minutes. ${ }^{34}$ The objective of this study was to evaluate the pharmacokinetic profile and safety and tolerability of administering rapid infusion intravenous ibuprofen. The intravenous ibuprofen formulation was considered equivalent to the oral therapy. More importantly, minor infusion related reactions were documented. Four patients experienced pain upon infusion while no patients experienced burning while receiving intravenous ibuprofen. All four of the adverse events resolved and no subsequent changes in vital signs were noted. Therefore, intravenous ibuprofen may be administered safety over 5 to 7 minutes if needed with minimal infusion related adverse effects.

\section{Invasive group A streptococcal infections}

The use of NSAIDS has been associated with invasive group A beta-hemolytic streptococcal infections including necrotizing skin and soft tissue infections. ${ }^{57-59}$ Associations have been strongest in pediatric patients and those with a previous varicella infection. ${ }^{60,61}$ Determination of a true causal relationship is difficult for several reasons including the ubiquitous use of NSAIDs, inherent limitations of the retrospective study design, and overall relatively low incidence of necrotizing GAS infections. NSAID therapy may delay diagnosis of invasive infections when used for antipyretic and analgesic effects early in the disease process. ${ }^{57-59}$ Alternatively, COX inhibition may blunt the immune response and decrease leukocyte activity and endothelial interactions at the site of infection. ${ }^{62,63}$

\section{Bone effects}

Several studies have proven that nonspecific NSAIDS may inhibit new bone growth and interrupt fracture healing. ${ }^{64,65}$ Recently, Goodman and colleagues conducted a study in rabbits comparing a non-specific COX-1 and COX-2 inhibitor, and a specific COX-2 inhibitor to determine differences in bone ingrowth and tissue differentiation. ${ }^{66}$ By using a titanium implant, or harvest chamber, researchers were able to monitor new bone growth in New Zealand white rabbits after administration of NSAIDS. The researchers found that when administered naproxen (non-specific COX-1 and COX-2 inhibitor), tissue bone ingrowth decreased by $15.9 \%$ versus $18.5 \%$ with the rofecoxib (selective COX-2 inhibitor). Although these results were not statistically significant, the authors concluded that bone ingrowth or fracture healing may be delayed when agents with COX-2 inhibitory properties are used. Because the bone healing of rabbit is very similar to humans, these data can be applicable. The authors concluded that patients should not take COX-2 inhibitors for at least 6 weeks following a fracture or implant procedure, although the duration of effect is still currently under research.

\section{Summary of safety and tolerability}

Overall data indicate a similar safety and tolerability profile with intravenous and oral ibuprofen. 
Cardiovascular thrombotic events, gastrointestinal effects, bleeding, hypertension, renal effects, anaphylactoid reactions, and bronchospasm have all been observed with oral ibuprofen therapy. Many of these side effects were not observed in studies of intravenous ibuprofen, but are still possible. The short study durations and inclusion of patients with few co morbidities reduced the likelihood of these adverse events during studies of intravenous ibuprofen. In addition, the longer duration of oral ibuprofen therapy is a likely contributor to the cardiovascular thrombotic effects, bleeding events, and renal effects. The potential for cardiovascular thrombotic events make ibuprofen a less desirable option for post-operative pain secondary to cardiac or vascular surgery procedures. In addition, although no adverse effects on renal function were observed in trials of intravenous ibuprofen it should be used with caution in patients with underlying renal disease. Patients with a history of bleeding also may be poor candidates for therapy with intravenous ibuprofen, and patients with a history of GI bleeding should not receive intravenous ibuprofen. These patients were excluded from clinical trials and an increased risk of bleeding was not observed. However, the GI side effects from ibuprofen arise from both topical injury and COX-1 inhibition, which is present even when a parenteral formulation is used. ${ }^{67}$ For reasons detailed above, although most of these side effects are not experienced in trials of intravenous ibuprofen, the manufacturer still details these precautions for the intravenous formulation.

\section{Summary and recommendations}

Intravenous ibuprofen is an attractive option for the treatment of pain in the acute post-operative setting and for use in the critically ill population. Data in a relatively small number of patients demonstrate its efficacy in reducing opioid requirements and pain scores relative to placebo in a variety of post-operative settings including abdominal and orthopedic procedures. In addition, data support its efficacy in reducing fever in the acute and critical care settings. Doses of 400 to $800 \mathrm{mg}$ are recommended for both analgesic and antipyretic effects in these settings. In the critically ill population, higher single doses of 800 mg should be considered to maximize desired effects. Although a 30-minute infusion is recommended, data on the safe use of a rapid infusion of 5 to 7 minutes are encouraging for ease of administration and optimizing rapid onset. Recognition of injection site pain with intravenous administration is important, specifically when employing a rapid infusion.
Although chronic or long-term therapy is not likely with the intravenous dosage form, extended use in the hospitalized patient should be anticipated. Extra caution and monitoring are required in patients for extended use and those with significant co-morbidities, including those undergoing cardiac or vascular procedures. Post-marketing surveillance will be critical as intravenous ibuprofen becomes more widely used. Current studies include relatively small numbers of patients, making differences in adverse events difficult to detect. They also followed patients for relatively short periods of time, and toxicities are more likely to be seen with prolonged therapy ${ }^{67}$ At this time, intravenous ibuprofen appears to be a useful adjunct for short-term use in post-operative pain in adult patients without significant underlying disease states and for potential use in critically ill patients for desired antipyresis.

\section{Disclosures}

The authors declare no conflicts of interest.

\section{References}

1. Rathmell JP, Wu CL, Sinatra RS, et al. Acute post-surgical pain management: a critical appraisal of current practice, 2005 Dec 2-4. Reg Anesth Pain Med. 2006;31:1-42.

2. Lee TS. Intensive Care anethesia and analgesia. In: Bongard FSSD, Vintch JR, editor. Current Diagnosis and Treatment: Critical Care. 3rd ed. New York, NY: McGraw Hill; 2008:97-116.

3. Southworth S, Peters J, Rock A, Pavliv L. A multicenter, randomized, double-blind, placebo-controlled trial of intravenous ibuprofen 400 and $800 \mathrm{mg}$ every 6 hours in the management of postoperative pain. Clin Ther. 2009;31:1922-1935.

4. Miaskowski C BM, Chou R, D’Arcy Y, Hartwick C, Huffman L, Maleki J, Manwarren R, editor. Principles of Analgesic Use in the Treatment of Acute Pain and Cancer Pain. 6th ed. New York, NY: American Psychological Society; 2008.

5. Cancer, pain relief and palliative care. World Health Organization. Geneva: WHO Technical Report Series; 1990.

6. Bertagnolli MM, Eagle CJ, Zauber AG, et al. Five-year efficacy and safety analysis of the Adenoma Prevention with Celecoxib Trial. Cancer Prev Res. 2009;2:310-321.

7. Bertagnolli MM, Eagle CJ, Zauber AG, et al. Celecoxib for the prevention of sporadic colorectal adenomas. N Engl J Med. 2006;355:873-884.

8. Roumie CL, Choma NN, Kaltenbach L, Mitchel EF Jr, Arbogast PG, Griffin MR. Non-aspirin NSAIDs, cyclooxygenase-2 inhibitors and risk for cardiovascular events-stroke, acute myocardial infarction, and death from coronary heart disease. Pharmacoepidemiol Drug Saf. 2009; 18:1053-1063.

9. Shafer SL. Retraction notice. Anesth Analg. 2009;108:1351.

10. Vane JR, Botting RM. New insights into the mode of action of antiinflammatory drugs. Inflamm Res.1995;44:1-10.

11. Marik PE. Fever in the ICU. Chest. 2000;117:855-869.

12. Kauffman RE, Nelson MV. Effect of age on ibuprofen pharmacokinetics and antipyretic response. J Pediatr. 1992;121:969-973.

13. McIntyre J, Hull D. Comparing efficacy and tolerability of ibuprofen and paracetamol in fever. Arch Dis Child. 1996;74:164-167.

14. Toradol [package insert]. Nutley, NJ: Roche Pharmaceuticals; 2002.

15. Arora S, Wagner JG, Herbert M. Myth: parenteral ketorolac provides more effective analgesia than oral ibuprofen. Can J Emerg Med. 2007;9:30-32. 
16. Todd PA, Clissold SP. Tenoxicam. An update of its pharmacology and therapeutic efficacy in rheumatic diseases. Drugs. 1991;41:625-646.

17. Lloyd R, Derry S, Moore RA, McQuay HJ. Intravenous or intramuscular parecoxib for acute postoperative pain in adults. Cochrane Database Syst Rev. 2009:CD004771.

18. Leeson RM, Harrison S, Ernst CC, et al. Dyloject, a novel injectable diclofenac formulation, offers greater safety and efficacy than voltarol for postoperative dental pain. Reg Anesth Pain Med. 2007;32:303-310.

19. Ibuprofen: Martindale - The Complete Drug Reference; 2009.

20. Neoprofen [package insert]. Deerfield, IL: Ovation Pharmaceuticals; 2006.

21. Smyth E, FitzGerald G. The eicosanoids: prostaglandins, thromboxanes, leukotrienes, and related compounds. In: Katzung B, editor. Basic and Clinical Pharmacology. 11th ed. New York, NY: McGraw-Hill.

22. Furst D, Ulrich R, Varkey-Altamirano C. Non-steroidal anti-inflammatory drugs, disease modifying antirheumatic drugs, non-opioid analgesics, and drugs used in gout. In: Katzung B, editor. Basic and Clinical Pharmacology. 11th ed. New York, NY: McGraw-Hill.

23. Bernard GR, Wheeler AP, Russell JA, et al. The effects of ibuprofen on the physiology and survival of patients with sepsis. The Ibuprofen in Sepsis Study Group. N Engl J Med. 1997;336:912-918.

24. Arons MM, Wheeler AP, Bernard GR, et al. Effects of ibuprofen on the physiology and survival of hypothermic sepsis. Ibuprofen in Sepsis Study Group. Crit Care Med. 1999;27:699-707.

25. Cadolor [package insert]. Nashville, TN: Cumberland Pharmaceuticals; 2009.

26. Bridoux F, Hazzan M, Pallot JL, et al. Acute renal failure after the use of angiotensin-converting-enzyme inhibitors in patients without renal artery stenosis. Nephrol Dial Transplant. 1992;7:100-104.

27. Packer M. Interaction of prostaglandins and angiotensin II in the modulation of renal function in congestive heart failure. Circulation. 1988;77:I64-73.

28. Bookstaver PB, Norris L, Rudisill C, DeWitt T, Aziz S, Fant J. Multiple toxic effects of low-dose methotrexate in a patient treated for psoriasis. Am J Health Syst Pharm. 2008;65:2117-2121.

29. Brown RD, Wilson JT, Kearns GL, Eichler VF, Johnson VA, Bertrand KM. Single-dose pharmacokinetics of ibuprofen and acetaminophen in febrile children. J Clin Pharmacol. 1992;32:231-241.

30. Kelley MT, Walson PD, Edge JH, Cox S, Mortensen ME. Pharmacokinetics and pharmacodynamics of ibuprofen isomers and acetaminophen in febrile children. Clin Pharmacol Ther. 1992;52:181-189.

31. Albert KS, Gillespie WR, Wagner JG, Pau A, Lockwood GF. Effects of age on the clinical pharmacokinetics of ibuprofen. Am J Med. 1984;77:47-50

32. Walson PD, Mortensen ME. Pharmacokinetics of common analgesics, anti-inflammatories and antipyretics in children. Clin Pharmacokinet. 1989; $17: 116-137$.

33. Morris PJ, Guntapalli K, Wright P, Bernard G. A multi-center, randomized, double-blind, placebo-controlled trial of the efficacy and safety of intravenous ibuprofen in febrile adults. Society of Critical Care Medicine Annual Congress. Honolulu, HI; 2008.

34. Pavliv LR. A randomized, double-blind, placebo-controlled, single dose, crossover study of the pharmacokinetics, safety and tolerability of ibuprofen injection in healthy adult volunteers. American Society of Health System Pharmacists Midyear Clinical Meeting. Las Vegas, NV; 2009.

35. Cumberlond Pharmaceuticals. Efficacy (fever and pain) and safety study of Caldolor in hospitalized burn patients NCT 00606489; Data on File.

36. Wilson JT, Brown RD, Kearns GL, et al. Single-dose, placebo-controlled comparative study of ibuprofen and acetaminophen antipyresis in children. J Pediatr. 1991;119:803-811.

37. Kokki H, Kumpulainen E, Lehtonen M, et al. Cerebrospinal fluid distribution of ibuprofen after intravenous administration in children. Pediatrics. 2007;120:e1002-e1008.

38. Bannwarth B, Lapicque F, Pehourcq F, et al. Stereoselective disposition of ibuprofen enantiomers in human cerebrospinal fluid. Br J Clin Pharmacol. 1995;40:266-269.
39. Barbato F, La Rotonda MI, Quaglia F. Interactions of nonsteroidal antiinflammatory drugs with phospholipids: comparison between octanol/buffer partition coefficients and chromatographic indexes on immobilized artificial membranes. J Pharm Sci. 1997;86:225-229.

40. Lee G, Dallas S, Hong M, Bendayan R. Drug transporters in the central nervous system: brain barriers and brain parenchyma considerations. Pharmacol Rev. 2001;53:569-596.

41. Khamdang S, Takeda M, Noshiro R, et al. Interactions of human organic anion transporters and human organic cation transporters with nonsteroidal anti-inflammatory drugs. J Pharmacol Exp Ther. 2002;303:534-539.

42. Bodo A, Bakos E, Szeri F, Varadi A, Sarkadi B. The role of multidrug transporters in drug availability, metabolism and toxicity. Toxicol Lett. 2003;140-141:133-143.

43. Mannila A, Kokki H, Heikkinen M, et al. Cerebrospinal fluid distribution of ketoprofen after intravenous administration in young children. Clin Pharmacokinet. 2006;45:737-743.

44. Mannila A, Kumpulainen E, Lehtonen M, et al. Plasma and cerebrospinal fluid concentrations of indomethacin in children after intravenous administration. J Clin Pharmacol. 2007;47:94-100.

45. Han EE, Beringer PM, Louie SG, Gill MA, Shapiro BJ. Pharmacokinetics of Ibuprofen in children with cystic fibrosis. Clin Pharmacokinet. 2004;43:145-156.

46. Konstan MW, Hoppel CL, Chai BL, Davis PB. Ibuprofen in children with cystic fibrosis: pharmacokinetics and adverse effects. J Pediatr. 1991;118:956-964.

47. Cumberlond Pharmaceuticals. Concentration/Stability in Diluents; Data on File.

48. Cumberlond Pharmaceuticals. A Multi-Center, Randomized, Double Blind, Placebo Controlled Trial of Ibuprofen Injection for treatment of pain in post-operative adult patients (abdominal hysterectomy pain study); Data on File.

49. Kroll PML, Rock A, Kaelin B, Pavliv L. Intravenous ibuprofen for the management of postoperative pain in adults. American Academy of Pain Management Annual Meeting. Phoenix, AZ; 2009.

50. Cumberlond Pharmaceuticals. NCT00470600, Efficacy and Safety Study of Caldolor in Hospitalized Adult Orthopedic Patients; Data on File.

51. Caldolor injection demonstrates significant fever reduction in hospitalized burn patients. http://www.medicalnewstoday.com/articles/171906. php Accessed Jan 5, 2010.

52. Gurfinkel EP, Guerlloy FP, Mautner B. Suppression of life-threatening tachyarrhyhmias, and atrio-ventricular ischemic block following the administration of anti-inflammatory intravenous drug. Int J Cardiol. 2007;114:E56-E57.

53. Van Overmeire B, Smets K, Lecoutere D, et al. A comparison of ibuprofen and indomethacin for closure of patent ductus arteriosus. N Engl J Med. 2000;343:674-681.

54. Lago P, Bettiol T, Salvadori S, et al. Safety and efficacy of ibuprofen versus indomethacin in preterm infants treated for patent ductus arteriosus: a randomised controlled trial. Eur J Pediatr. 2002;161:202-207.

55. CherifA, Khrouf N, Jabnoun S, et al. Randomized pilot study comparing oral ibuprofen with intravenous ibuprofen in very low birth weight infants with patent ductus arteriosus. Pediatrics. 2008;122:e1256-e1261.

56. Cumberlond Pharmaceuticals. NCT00606489, Efficacy (fever and pain) and safety of Caldolor in hospitalized burn patients; Data on File.

57. Aronoff DM, Bloch KC. Assessing the relationship between the use of nonsteroidal antiinflammatory drugs and necrotizing fasciitis caused by group A streptococcus. Medicine (Baltimore). 2003;82:225-235.

58. Souyri C, Olivier P, Grolleau S, Lapeyre-Mestre M. Severe necrotizing soft-tissue infections and nonsteroidal anti-inflammatory drugs. Clin Exp Dermatol. 2008;33:249-255.

59. Factor $\mathrm{SH}$, Levine OS, Harrison LH, et al. Risk factors for pediatric invasive group A streptococcal disease. Emerg Infect Dis. 2005;11:1062-1066.

60. Peterson CL, Vugia DJ, Meyers HB, et al. Risk factors for invasive group A streptococcal infections in children with varicella: a case-control study. Pediatr Infect Dis J. 1996;15:151-156. 
61. Zerr DM, Alexander ER, Duchin JS, Koutsky LA, Rubens CE. A case-control study of necrotizing fasciitis during primary varicella. Pediatrics. 1999;103:783-790.

62. Aronoff DM, Neilson EG. Antipyretics: mechanisms of action and clinical use in fever suppression. Am J Med. 2001;111:304-315.

63. Barnham M. Nonsteroidal antiinflammatory drugs: concurrent or causative drugs in serious infection? Clin Infect Dis. 1997;25:1272-1273.

64. Allen HL, Wase A, Bear WT. Indomethacin and aspirin: effect of nonsteroidal anti-inflammatory agents on the rate of fracture repair in the rat. Acta Orthop Scand. 1980;51:595-600.
65. Altman RD, Latta LL, Keer R, Renfree K, Hornicek FJ, Banovac K. Effect of nonsteroidal antiinflammatory drugs on fracture healing: a laboratory study in rats. J Orthop Trauma. 1995;9:392-400.

66. Goodman S, Ma T, Trindade M, et al. COX-2 selective NSAID decreases bone ingrowth in vivo. J Orthop Res. 2002;20:1164-1169.

67. Wolfe MM, Lichtenstein DR, Singh G. Gastrointestinal toxicity of nonsteroidal antiinflammatory drugs. N Engl J Med. 1999;340:1888-1899.

\section{Publish your work in this journal}

The Journal of Pain Research is an international, peer-reviewed, open access, online journal that welcomes laboratory and clinical findings in the fields of pain research and the prevention and management of pain. Original research, reviews, symposium reports, hypothesis formation and commentaries are all considered for publication.

\section{Dovepress}

The manuscript management system is completely online and includes a very quick and fair peer-review system, which is all easy to use. Visit http://www.dovepress.com/testimonials.php to read real quotes from published authors. 